\title{
UTILISATION OF RICE HUSK ASH FOR IMPROVEMENT OF DEFICIENT SOILS IN NIGERIA: A REVIEW
}

\author{
M. Alhassan ${ }^{1,{ }^{*}}$ and M. M. Alhaji ${ }^{2}$ \\ 1, 2 DEPARTMENT OF CIVIL EngineERING, FEDERAL UnivERSITy OF TECHNOLOGY, MinNA, NigER STATE. NIGERIA \\ Email addresses:1 alhassankuta@futminna.edu.ng,2a.mustapha@futminna.edu.ng
}

\begin{abstract}
Review of studies, mostly carried out at laboratory scale, on the utilisation of Rice Husk Ash (RHA) for improvement of deficient soils in Nigeria is presented. Although, few studies have focused on using the RHA as soil improving additive alone, most of the studies have been on its usage as additive to the conventional soil stabilizers (cement and lime). The studies generally showed improvement in the geotechnical properties of soils, either modified or stabilised with the ash, thus indicating the potentials of using this agricultural waste for improvement of geotechnical properties of deficient soils. This suggest that using this material at large scale level in geotechnical engineering practice will help in the provision of stable and durable geotechnical structures, reduce cost of soil improvement and the environmental nuisance caused by the unused waste. This will considerably add to the economic value chain of rice farmers/producers in Nigeria.
\end{abstract}

Keywords: Black cotton soil, Deficient soil, Laterite, Rice husk ash, Soil improvement.

\section{INTRODUCTION}

Soil improvement has become a major issue in construction and geotechnical engineering practice, and research especially on the effective utilisation of industrial wastes in soil improvement is rapidly increasing [1]. Deficient soils are regarded as soils which do not meet some or all the criteria required for their satisfactory performance as geotechnical structures. These could either be for base courses for road, embankment for dam or road, subsoil base for foundation, clay liners for containment of leachates and backfill for retaining walls [2]. In the tropical region, these soils could be lateritic soils, black cotton soils, collapsible soils or any other tropical soils.

According to Gidigasu [3], laterite is a soil group, which is commonly found in the leached soils of the humid tropics and is formed under weathering systems that allow laterization process. Ochepo et al. [4] stated that the dominant soil material available for the construction of sub-base and base courses for both flexible and rigid pavements in Nigeria and other tropical regions of the world is lateritic soil. This is attributed to its abundance and cost effectiveness. Although, Osinubi and Bajeh [5], states that a lot of lateritic gravels and pisoliths that can be adjudged good for roads bases occur in tropical countries of the world, including Nigeria, there are instances where laterite may contain substantial amount of clay minerals that rendersits strength and stability under load, especially in the presence of moisture, unguaranteed. These types of laterites are also common in many tropical countries including Nigeria where in most cases sourcing for alternative soil usually proves economically unwise. In such cases, improvement of the available soil to meet or acquire the desired properties is usually opted for [6].

Black cotton soils are expansive soils that principally occur in arid and semi-arid regions of the tropical/temperate zones marked with dry and wet seasons, with low rainfall, poor drainage and exceeding great heat $[7,8]$. Because of their unconventional behaviour, black cotton soils are problematic in geotechnical engineering practice. They form a major soil group found in North Eastern part of Nigeria and exhibit large volume changes with respect to variation of seasonal moisture content [9]. They pose challenges to civil engineering works because of their swelling and shrinkage characteristics. They are usually very hard when dry, but losses their strength when wet. They exhibit very low bearing capacity, low permeability and high volume change due to the presence of montmorillonite and illite clay minerals in them. These properties make the soils in their natural state unsuitable for geotechnical engineering constructions [10].

Improvement of deficient soils could either be by modification or stabilisation or both. While modification is improvement of soil by addition of a modifier (cement, lime etc) to change (improve) its index properties, soil 
stabilisation is the treatment of soils to enable improvement of their strength and durability such that they become totally suitable for construction beyond their original classification. Over time, cement and lime have been the two main materials used for stabilising soils. According to Neville [11], the cost of these materials has rapidly increased due to the sharp increase in the cost of energy since 1970s.

The cost of construction of roads with stabilised layers and other geotechnical structures has continued to remain high due to the over dependent on the utilisation of industrially manufactured soil improving additives (cement, lime etc.). This has consequently continued to deter the underdeveloped and poor nations of the world from providing accessible roads to their rural dwellers, who constitute the higher percentage of their population and are mostly, agriculturally dependent [12]. Thus the use of agricultural waste (such as Rice Husk Ash) will considerably reduce the cost of construction, the environmental hazards these wastes cause as well as economically, add to the value chain of the rice farmers. Information on world rice production [13], shows that the global rice production by $2015 / 2016$ season was 472.09 million tons, while for $2016 / 2017$, it is estimated to be 483.26 million tons, representing an increase of 11.17 million tons $(2.37 \%)$ rise in the production. This translate to about 157.2 and 160.9 million tons of rice husk for 2015/2016 and 2016/2017 respectively, with corresponding increase of $2.37 \%$ over these two seasons [13]. About 2.0 million tons of rice is produced annually in Nigeria [14]. Wailes and Chavez [15] projected rice production in Nigeria for 2016/2017 season to stand at 3.120 million metric tons. This explained why mountain heaps of the husk has become common sites at milling points, in Nigeria and other developing countries. The search for potential use of this waste, especially in geotechnical engineering, has prompted researchers over the last few years to study how it can be used in the improvement of soils. Burning of rice husk generates up to $25 \%$ of its weight as ash [16 - 20]. This will eventually help in the disposal of this waste material and reducing its hazardous effects on the environment. According to Oyetola and Abdullahi [14], the ash has been categorized as pozzolana, with about $67-70 \%$ silica and about 4.9 and $0.95 \%$ aluminum and iron oxides, respectively. Akinyele, et al. [17] also reported $67.27 \%$ silica in rice husk ash, while Akeke et al. [21] reported silica content of up to $84.55 \%$. The silica is substantially contained in amorphous form, which can react with the $\mathrm{CaOH}$ librated during the hardening of cement to further produce cementitious compounds.

It was reported by Sear [22] that Portland Cement, by the nature of its chemistry, produces large quantities of $\mathrm{CO}_{2}$ for every ton of its final product. Therefore, replacing proportions of the Portland cement in soil stabilisation with a secondary cementitious material like rice husk ash will reduce the overall environmental impact of the stabilization process. Researches have recently been focused on the utilisation of rice husk ash for the improvement of geotechnical characteristics of deficient soils in Nigeria. A review of some of these studies is presented below.

\section{UTILISATION OF RICE HUSK ASH FOR IMPROVEMENT OF LATERITIC SOILS}

Studies have been carried out on the use of Rice Husk Ash (RHA) for improvement of the geotechnical properties of lateritic soils. Rahman [23] carried out series of laboratory tests to examine the influence of well-burnt rice husk ash on geotechnical properties of lateritic soil. The results of the study indicated the liquid limit, plastic limit, optimum moisture content, unconfined compressive strength, California bearing ratio value, cohesion, angle of internal friction as well as shear strength of the lateritic soil increased with increase RHA content. The unconfined compressive strength, California bearing ratio and shear strength parameters of the RHA treated soil samples were highest around 17\% rice husk ash content, indicating 17\% RHA content as the optimum, required to economically stabilise the soil for sub-base materials in highway construction. The study did not evaluate the RHA treated lateritic soil for other geotechnical structures other than sub-base materials for road construction.

Alhassan and Mustapha [12] investigated the effect of RHA on cement stabilised laterite using an A-7-6 laterite soil collected from Maikunkele area of Minna, Niger State, Nigeria. The soil was stabilised with 2 to $8 \%$ cement. Effect of RHA on the soil was investigated with respect to compaction characteristics, California Bearing Ratio (CBR) and Unconfined Compressive Strength (UCS) tests at British Standard Light (BSL) compaction energy. Results obtained, indicate a general decrease Maximum Dry Density (MDD) and increase Optimum Moisture Content (OMC) with RHA content (2 to 8\%) at specified cement contents. Tremendous improvement in the CBR (Figure 1) and UCS (Figure 2) with increase in the RHA content at specified cement contents, to their peak values which lies between 4 and 6\% RHA. The UCS values also improved with curing age, thus indicating the potentials of using 4 and 6\% RHA, admixed with less cement contents for laterite soil stabilisation. The study also only evaluated the treated soil for use as base and sub-base materials for road construction. 


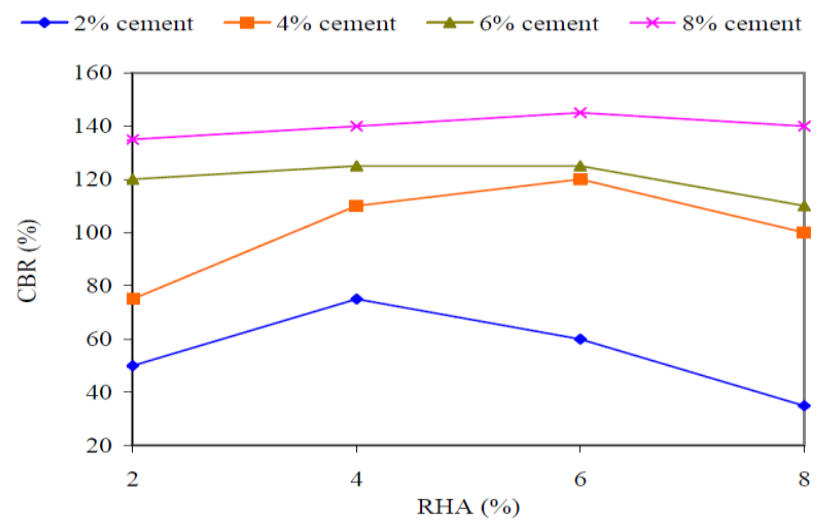

Figure 1: Variation of CBR with RHA content (source: [12])

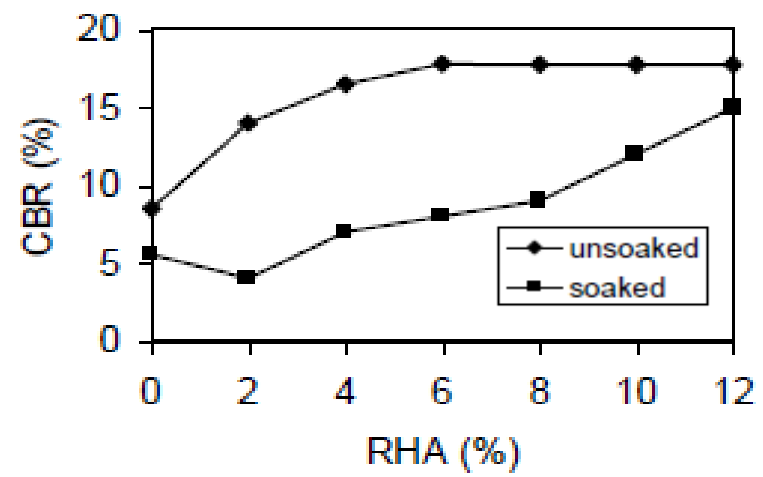

Figure 3: Variation of CBR with RHA content (source: [24])

Alhassan [24] investigated the potentials of RHA for soil stabilisation. Using lateritic soil sample collected from Maikunkele area of Minna, classified as an A-7-6 soil using AASHTO classification system, 2 to $12 \%$ RHA by weight of the dry soil was employed for the stabilisation. Performance of the soil-RHA was investigated at BSL compaction energy level, with respect to compaction characteristics, CBR and UCS tests. Results of study indicated general decrease in the MDD and increase in OMC with RHA content. The study also recorded slight improvement in the CBR and UCS with the RHA content (Figure 3 and 4). The peak UCS values were recorded between 6 to 8\% RHA, indicating relatively little potential of using 6 to 8\% RHA for strength improvement of A-7-6 lateritic soil. Performance of the treated soil when used for other geotechnical structures other than road bases was not considered.

In a related study, Okafor and Okonkwo [25] investigated the effects of rice husk ash on some geotechnical properties of lateritic soil, using lateritic soil classified as an A-2-6 (0) according to AASHTO classification system for sub-grade purposes. The investigation included evaluation of properties such as compaction, consistency limits and strength of the soil with RHA content of 5, 7.5, 10 and $12.5 \%$ by weight of the dry soil. Results obtained showed that increase in RHA content increased the OMC but decreased the MDD. It was also observed that increase in RHA content, reduced plasticity and

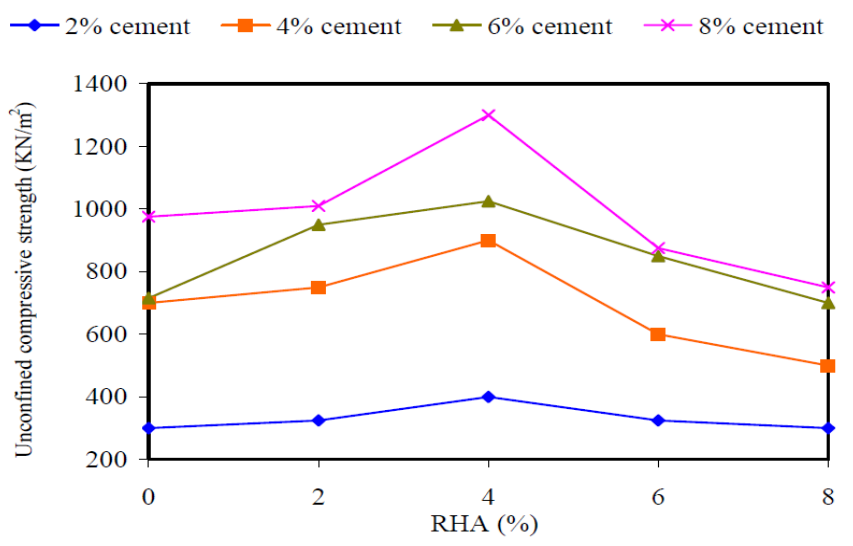

Figure 2: Variation of 28 days UCS with RHA content (source: [12])

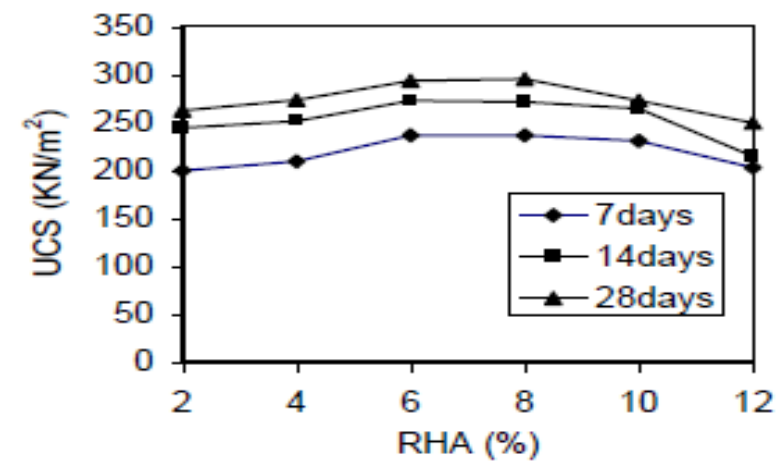

Figure 4: Variation of UCS with RHA content (source: [24])

increased volume stability as well as the strength of the soil. 10\% RHA content was observed to be the optimum content (Figure 5). The study only considered properties used for evaluating performance of the soil as road bases. Performance of the treated soil under other geotechnical structures like embankment was not evaluated.

In another study, Alhassan [26] investigated permeability of lateritic soil treated with lime and RHA, using A-7-6 lateritic soil and compacted at BSL compaction energy with up to $8 \%$ lime content (by dry weight of the soil) at $2 \%$ variations. Each of the soil-lime mixture was admixed with up to $8 \%$ RHA at $2 \%$ variations. Effects of the ash on the soil-lime mixtures were investigated with respect to UCS and coefficient of permeability. Results of the study showed increased in UCS of the specimens with increasing RHA content at specified lime contents to maximum values at $6 \%$ RHA content. The coefficient of permeability of the cured specimens decreased with increase in the ash content to their minimum values at $6 \%$ RHA content, and beyond this point, the permeability slightly rises (Figure 6). The author concluded that not more than 6\% RHA can be used to increase UCS and reduce permeability of lateritic soil. The study considered only one compaction energy level (BSL). Other compaction energy levels (West African Standard-WAS and British Standard Heavy-BSH), which could had apparently yielded less permeability values, were not considered. 


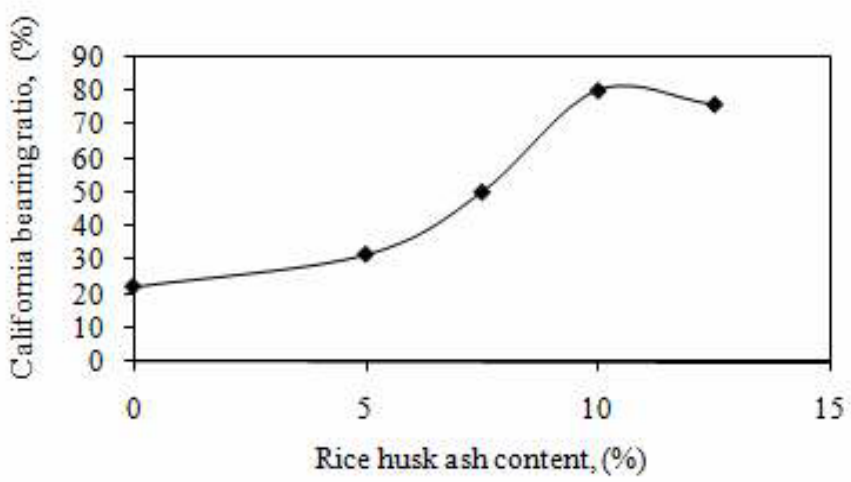

Figure 5: Variation of CBR with Rice Husk Ash content (source: [25])

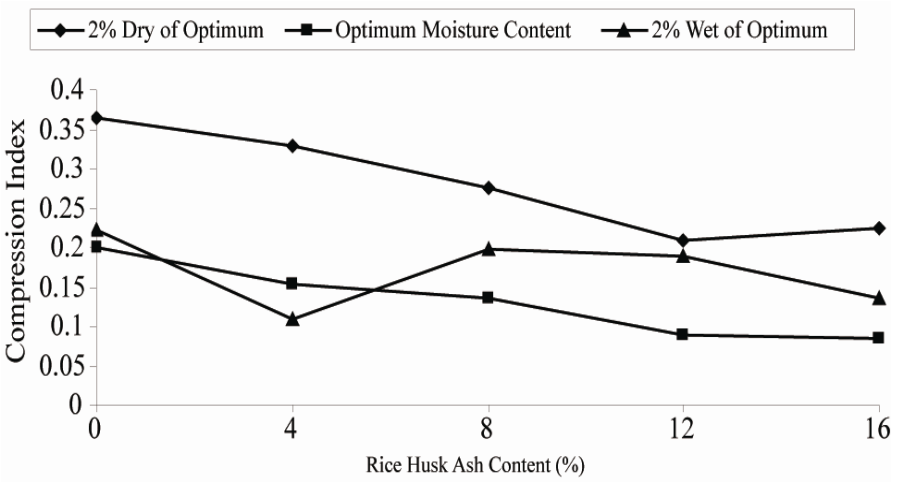

Figure 7: Variation of compression index with RHA content (source: [18])

In a related study, Alhassan [27], investigated permeability of cement-rice husk ash treated lateritic soil. A-7-6 lateritic soil was compacted at BSL compaction energy with up to $8 \%$ cement, by dry weight of the soil, at $2 \%$ variations and each admixed with up to $8 \%$ RHA at $2 \%$ variations. Effect of the ash on the soilcement mixtures were studied with respect to MDD, OMC and coefficient of permeability. Result of the study showed MDD of the soil-cement specimens decreasing with increasing RHA content at specified cement contents to their minimum values at $6 \%$ RHA content. The OMC increased with increasing percentages of the ash. The coefficient of permeability of the cured specimens decreased with increase in the ash content to their minimum values at $4 \%$ RHA content. Beyond $4 \%$ RHA content, no significant reduction of the coefficient of permeability was observed, indicating that not more than $4 \%$ RHA can be used with cement to attenuate permeability of A-7-6 lateritic soil. Only one compaction energy level (BSL) was considered in the study. Higher compaction energy levels (West African Standard-WAS and British Standard Heavy-BSH), which could had apparently yielded lower permeability values, were not considered.

Mtallib and Bankole [28] used lime and RHA to experimentally study improvement of index properties

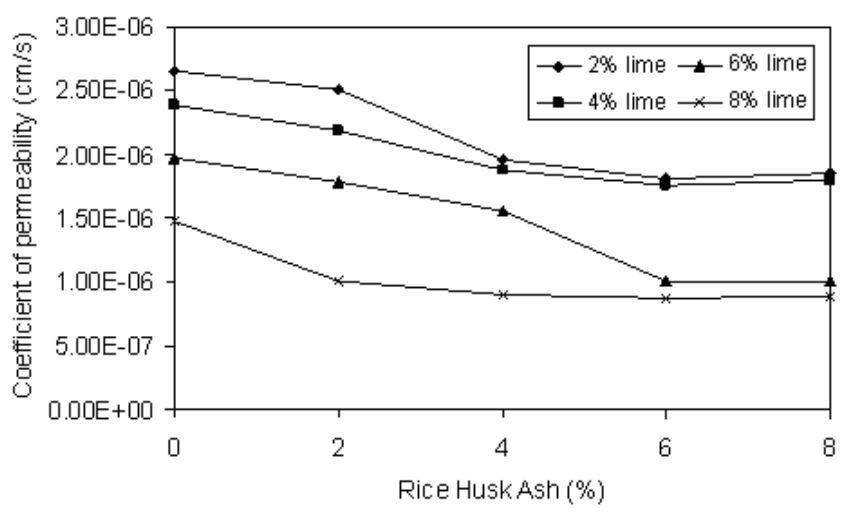

Figure 6: Variation of 28-day Permeability with $R H A$ Content(source: [26])

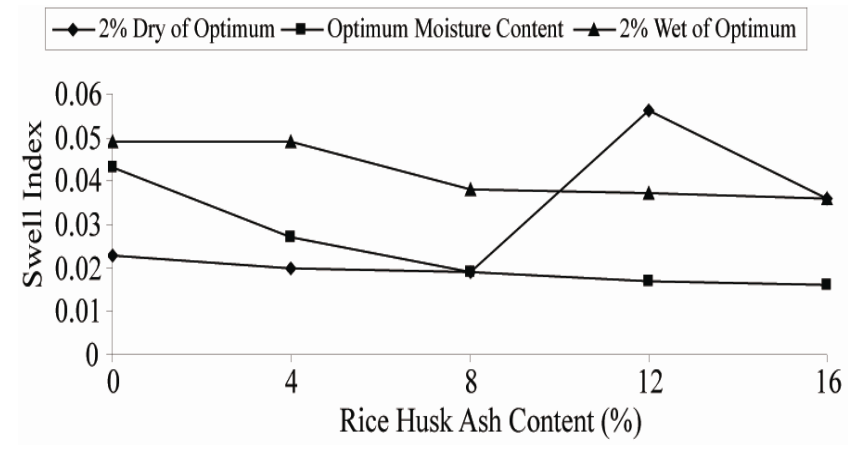

Figure 8: Variation of swell index with RHA content (source: [18])

and compaction characteristics of tropical lateritic clays. The two A-7-6 soils studied, showed significant improvement in properties. The Atterberg limits were significantly altered with lime and rice husk ash combination; the plasticity of the soils significantly reduced with addition of lime and the ash. MDD and OMC decreased and increased respectively, on addition of lime and RHA. The unsoaked California Bearing Ratio (CBR) values peaked at $8 \%$ lime and $10 \%$ RHA combinations for one of the samples, while for the second sample, at relatively higher dosage of the additives, and thus, indicating the potentials of using lime-RHA to improve A7-6 tropical lateritic soil. Performance of the treated soil as road bases was considered, while its performance under other geotechnical structures other than road bases was not taken into consideration.

Eberemu [18] studied consolidation properties of compacted lateritic soil treated with RHA, using one dimensional laboratory consolidation test, conducted on compacted lateritic soils treated with up to $16 \%$ RHA. The Specimens were prepared at three different moulding water contents ( $2 \%$ dry of optimum, optimum moisture content and 2\% wet of optimum) and compacted using the BSL compactive effort. Preliminary tests on the soils showed improvement in the index properties with increase in liquid limit and plastic limits 
with resulting decrease in plasticity index. Reconsolidation pressure was also observed to increase with RHA content; it also decreased before increasing with increased moulding water content. Reductions in compression index (Cc) and swell index (Cs) with increased RHA content were recorded (Figure 7 and 8). Cc and Cs generally decreased before increasing with increased moulding water content. The coefficient of volume compressibility (Mv) decreased and increased with higher RHA content; they were also affected by the soil particle state with increasing pressure. The study showed no observable trend for coefficient of consolidation (Cv) with increased RHA content, but generally increased with higher consolidation pressure on the dry and wet side of optimum compacted states. The study considered only one compaction energy level (BSL). Higher compaction energy levels (West African Standard-WAS and British Standard Heavy-BSH), which could had apparently further reduced Cc and Cs, with increased RHA content were not considered.

Francis and Venantus [29] reported result of stabilisation of A-7-5, A-6 and A-2-7 soil from Eke Obinagu, Egbede and Ugwuaji, respectively. The CBR values increase from 5 to $29 \%, 7$ to $13 \%$ and 5 to $23 \%$ for A-7-5, A-6 and A-27 respectively, at optimal value of $17.5 \%$ of RHA. There was also an appreciable increase in the OMC values from 15 to $33 \%, 14$ to $25 \%$ and 15 to $31 \%$ for A-7-5, A-6 and A-2-7 soils respectively at $17.5 \%$ stabilisation with RHA. The study only evaluated the treated soils for use as road bases. Their performance under other geotechnical structures like dam embankment was not evaluated.

Ayininuola and Olaosebikan [30] studied influence of RHA on soil permeability, using four soil samples, sourced from four locations within Ibadan, Oyo State, Nigeria. Each soil sample was stabilised with varying percentages $(3,5,7,10$ and 15\%) of furnace-prepared RHA, which was composed of $79.66 \% \mathrm{SiO}_{2}, 2.21 \% \mathrm{Al}_{2} \mathrm{O}_{3}$, and $0.65 \% \mathrm{Fe}_{2} \mathrm{O}_{3}$, amongst other compounds. Coefficients of permeability of the stabilised soil samples were determined using falling head method. The results showed coefficient of permeability of the soil decreasing with increasing RHA content. This, according to the authors was due to exchangeable action of cations such as $\mathrm{Al}^{3+}$ and $\mathrm{Ca}^{2+}$ present in the ash with other monovalent ions forming strong bond that hindered passage of water. The study only considered samples compacted at West African Standard (WAS) energy level. Other compaction energy levels (British standard LightBSL and British Standard Heavy-BSH), were not considered.

Agwu and Akpan [31] carried out a comparative study of the use of RHA, fly ash, periwinkle shell and gypsum as stabilising agent for clay, using soil classified as an A6(11) soil. The test results showed that fly ash was the best stabilising material, followed by gypsum. The periwinkle shell did not increase the shear strength of the soil, while the RHA decreased it. The authors stated that, because of the silica content of RHA and fly ash, the specimens treated with them were expected to develop more shear strength with age, and therefore concluded that fly ash, gypsum, and RHA are good materials for clay soil stabilisation, because of the improved shear strength and ease of compaction which they impart. They were therefore, recommended for use in sandy clay soil stabilisation as they generally improve the engineering properties of such soils. The study did not clearly state the method or equation used in the determination of the shear strength $(\tau)$ of both the untreated and treated soils. This is because the normal shear strength equation (eqn 1) is a function of normal stress $\left(\sigma_{n}\right)$, angle of internal friction $(\phi)$ and cohesion (c) of a soil. In this regard, normal stress $\left(\sigma_{\mathrm{n}}\right)$ is stress normal to the shear plane, and therefore, is not the same as axial compressive stress.

$$
\tau=\sigma_{n} \tan \phi+c
$$

Negedu and Nwakonobi [19] evaluated properties of Makurdi lateritic clay-RHA bricks for pavements purposes. The study was undertaken to investigate the effect of RHA on the properties of the burnt Makurdi lateritic clay bricks. 3 to $15 \%$ RHA was blended with the clay. Compressive strength and water absorption test were conducted on each admixture. The clay bricks were burnt at three different temperatures: $700^{\circ} \mathrm{C}, 800^{\circ} \mathrm{C}$ and $900^{\circ} \mathrm{C}$, to ascertain the compressive strength property of the clay with temperature variation. Result showed that the plasticity index reduced gradually and had a minimum value of $19.23 \%$ at $9 \%$ RHA. The average compressive strength and water absorption of the burnt bricks at $700^{\circ} \mathrm{C}$ attained a maximum value of 4.79 $\mathrm{MN} / \mathrm{m}^{2}$. Abrasion resistance of the resulting burnt bricks was not considered in the study.

Alabi, et al. [20] evaluated RHA stabilised lateritic soil as sub-base in road construction, using laboratory experiments, with an A-7 soil. The soil was stabilised with $2.5 \%$ increment between 5 to $12.5 \%$ of RHA by dry weight of soil. Performance of the soil-RHA was investigated with respect to compaction characteristics, CBR and UCS tests. The result showed that addition of RHA decreased the maximum dry density, while the optimum moisture content increased. CBR results showed that the peak soaked CBR value was $135.5 \%$ at 7.5\% RHA content, which indicates $92.44 \%$ increase over the value for the natural soil. The lowest soaked CBR value occurred at $12.5 \%$ RHA content. The UCS test results showed that the strength for the natural soil was $107.32 \mathrm{~N} / \mathrm{mm}^{2}$ and the highest value for the stabilised 
soil was $68.82 \mathrm{~N} / \mathrm{mm}^{2}$ at 5\% RHA content, resulting in $40.5 \%$ decrease in the UCS of the natural soil. The authors concluded that, the study showed little potentials of using RHA only for soil improvement, and recommended that $5 \%$ of RHA be added during field stabilisation, for the purpose of improving the engineering properties of the laterite soil for pavement sub-base construction. They also suggested that to achieve high pozzolanic benefit, the RHA intended for use in stabilisation should be calcined burnt between $600^{\circ} \mathrm{C}$ and $700^{\circ} \mathrm{C}$ temperature. Two compaction energy levels (Standard Proctor and Modified Proctor) were reportedly used in the study, but the reported results indicated only one compaction energy level, which was also not clearly stated.

Isah [32] studied the effect of rice husk ash on the properties of clay soil, by evaluating the variations in compressive strength, developed between ordinary and improved compressed earth bricks, stabilised with RHA at different percentage ranging from 0 to $12.5 \%$ by weight of the dry soil, at $2.5 \%$ variations, and at 14,21 and 28 days curing periods. The clay soil used for the study was collected from Bambami village of Batagarawa Local government of Katsina state, Nigeria, while the Rice Husk was obtained from Dandume local government of the same state. Results revealed that, when stabilised with RHA, the compressed earth brick was comparable with other bricks in every respect and can perform well in modern construction work, and demonstrates properties comparable with conventional bricks, especially in terms of strength and durability. Other properties indicated increase in OMC and decrease in MDD with RHA content. Improvement in CBR and ultimate bearing capacity with RHA content was also observed. Results of the study indicate 10 and $12.5 \%$ as maximum dosage of RHA. The author concluded that, in areas where rice husk is available, RHA can be used as an alternative soil stabilising agent to improve properties of soft clay soil for the purpose of making compressed earth brick that are suitable for load bearing walls of buildings not more than two stories. The study did not clearly states the method used in determining the CBR of both the unimproved and improved compressed earth bricks. Akinyele, et al. [17] studied the use of RHA as a stabilising agent in lateritic clay soil, using rice husk, burnt in a controlled environment to form the ash. The RHA was mix with lateritic clay at $0,2,4,6,8$, and $10 \%$ proportion by weight of the dry soil. Particle size distribution, Atterberg limits, and density tests were carried out on the mix materials. From the results of particle size distribution and Atterberg limits, they concluded that RHA can be effectively used in hydraulic barriers and as a stabilizing agent. Although, the authors concluded that RHA can be effectively used in hydraulic barriers, permeability characteristics of the treated soil, which would have further ascertained this claim was not determined.

\section{UTILISATION OF RICE HUSK ASH FOR IMPROVEMENT OF BLACK COTTON AND OTHER EXPANSIVE SOILS}

Some studies have also been carried out on the use of rice husk ash on the improvement of black cotton soils and other expansive soils in Nigeria. Eberemu and Sada [33] studied compressibility characteristics of compacted black cotton soil treated with rice husk ash, using one dimensional consolidation. The consolidation characteristics of the black cotton soil samples, containing $0,4,8,12$, and $16 \%$ RHA were observed at different moulding water contents ( $2 \%$ dry of optimum, optimum moisture content and $2 \%$ wet of optimum), simulating different field placement conditions. Variations of the soil's index properties with ash treatment were also observed. Results showed improved index properties; plastic limit of the soil was found to increase, while the liquid limit and plasticity index decreased with increased RHA content. The optimum moisture content was observed to increase, while maximum dry density decreased with RHA content. The swelling pressure decreased with increased RHA content. The consolidation parameters also showed appreciable changes; with the gross yielding stress increasing with RHA content. The compression index decreased with increased RHA content (Figure 9) but increased with increasing moulding water content (Figure 10). The coefficient of volume compressibility and coefficient of consolidation generally decreased with increased loading pressure and RHA content up to $8 \%$. The coefficient of permeability decreased with RHA content up to $8 \%$. These results show an overall improvement in the consolidation properties up to $8 \%$ treatment; suggesting the suitability of the material in fills for embankment and low lying marginal land for foundation works. The authors concluded that this will also help in ameliorating the environmental problems associated with the disposal of waste rice husk ash. British Standard Light (BSL) compaction energy level was considered in the study. Higher compaction energy levels (West African Standard-WAS and British Standard Heavy-BSH), which could had apparently further reduced the coefficient of volume compressibility, coefficient of consolidation and coefficient of permeability of the treated soil.

Atuonye et al. [1] investigated the suitability of RHA for used in the local construction industry in a way to mitigate the problems caused by expansive clays. The study used clay soil samples with high plasticity, taken from Amuro-Okigwe. The soil was stabilized with different percentages of cement and cement/RHA mixtures. 


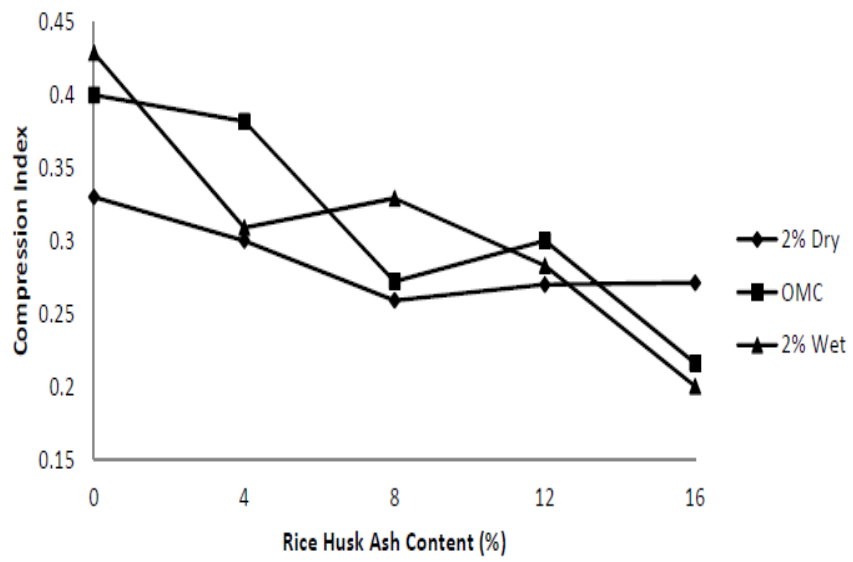

Figure 9: Variation of compression index with rice husk ash content (source: [33])

Changes in the soil's geotechnical properties, such as plastic limit, liquid limit, plasticity index and linear shrinkage were observed. The results of the study showed that increase percentages of cement and cement/RHA, changes the geotechnical properties of the soil. Optimal results were obtained at $8 \%$ of cement mixture, while for soil-cement-RHA mixtures, optimal results were obtained at ratio of 75:20:5 respectively. From the study, the authors recommended cement and cement/RHA for soil stabilisation for the construction of highway pavements and canal linings. The properties investigated in the study were limited in scope to enable giving a general recommendation for the treated material to be used for construction of highway pavements and canal linings.

Eberemu [34], using clay soil, collected within engineering complex of University of Agriculture, Makurdi, Benue, State, Nigeria, studied desiccation induced shrinkage of compacted tropical clay treated with rice husk ash. The tropical clay, which has illite as the dominant clay mineral, was treated with up to $16 \%$ RHA to evaluate its desiccation induced shrinkage and hence its suitability as a cover material in waste containment systems. The soil-RHA mixtures were compacted using three compactive efforts at $-2,0,2$ and $4 \%$ of OMC. The compacted samples were allowed to air dry in the laboratory for 30 days after which they were subjected to two cycles of wetting and drying. Results of the study showed that changes in mass and volumetric shrinkage strain (VSS) were largely within the first five days of drying and were affected by the compactive effort. The VSS was observed to increase with higher moulding water content, water content relative to optimum and RHA treatments. The VSS were also observed to be affected by the compactive effort, with acceptable compaction planes obtained for up to $12 \%$ RHA treatment. After two cycles of wetting and drying, the author observed that the rate of capillary rise within

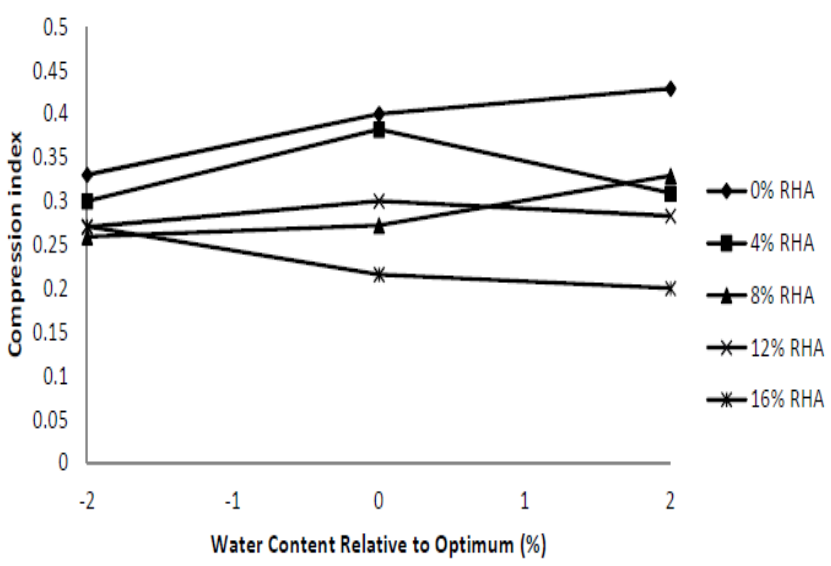

Figure 10: Variation of compression index with water content relative to optimum (source: [33])

the compacted soil increased with lower compactive effort and higher RHA treatment. Lower amount of cracking was observed in soil specimen with higher RHA treatment and higher cracking in soils with lower RHA content. Increased compactive effort reduced the effect of swelling during wetting; showing suitability of the material as a cover in municipal waste containment facility and beneficial reuse of this agro waste product.

Agbede and Joel [35] undertook a study to investigate the effect of RHA on the properties of burnt Ibaji clay bricks. The clay was blended with 2 to $10 \%$ RHA. Atterberg limits, specific gravity, compressive strength and water absorption tests were conducted on each of the resulting admixtures. X-ray diffraction and geochemical tests were performed on the RHA and the soil respectively. The Xray diffraction result showed the soil having mainly kaolinite clay mineral. Results of tests showed the plasticity index reducing to a minimum value at $6 \%$ RHA. The compressive strength and water absorption attained a maximum value of $18.64 \mathrm{MN} / \mathrm{m}^{2}$ and a minimum value of $14.8 \%$ respectively at $2 \%$ RHA. The authors therefore concluded that $2 \%$ RHA additive led to a significant improvement in the properties of Ibaji burnt clay brick. The moulding water, which was stated to be gotten from compaction test, earlier conducted on the treated materials, will eventually affect the result of the study. It was therefore necessary that the compaction energy level, used in the study, be stated clearly.

\section{CONCLUSION}

The paper generally reviewed studies carried out on the utilisation of rice husk ash in the improvement of deficient soils in Nigeria. The review generally showed potentials of using this agricultural waste for the improvement of geotechnical properties of deficient soils. This suggest that using this material at large scale level, in geotechnical engineering practice in Nigeria will help in the provision of stable and durable structures, 
reduce cost of soil improvement, reduces environmental nuisance the unused waste causes, and will considerably add to the economic value chain of the rice farmers/producers.

\section{REFERENCES}

[1] Atuonye, O. R., Okeke, O. C., Duru, B. L. and Onuemelu, O. C. "Laboratory Study of Stabilization of Expansive Soil from Amuro-Okigwe, Southeastern Nigeria, with Cement Mixtures and Cement/Rice Husk Ash", TLEP International Journal of Environmental Technology Research, vol. 1(7),, pp. 66-75. 2016.

[2] Alhassan, M. and Mustapha, A. M. "Improvement of Deficient Soils in Nigeria Using Bagasse Ash - A Review", Proceeding of 17th International Conference on Civil and Building Engineering, Dubai, pp. 1040-1049. 2015,

[3] Gidigasu, M. D. Laterite Soil Engineering: Paedogenesis and Engineering Principles, Elsevier Scientific Publication Company, Amsterdam, 1976.

[4] Ochepo, J., Salahudeen, A. B. and Iliyasu, I. "Strength Evaluation of Laterite Soil Mixed With Reclaimed Asphalt Pavement and Bagasse Ash for Sub-Base Construction", Retrieved from: http://www.researchgate.net/publication/265832 414. 2014.

[5] Osinubi, K. J. and Bajeh, I. "Bituminous Stabilization of Laterite”, Spectrum Journal, vol. 1(2), pp. 104112. 1994,

[6] Mustapha M. A."Effect of Bagasse Ash on Cement Stabilized Laterite", Seminar Paper Presented in the Department of Civil Engineering, Ahmadu Bello University, Zaria, Nigeria, 2005.

[7] Chen, F. H. Foundations on Expansive Soils, Elsevier Scientific Pub. Co. Amsterdam, 1988.

[8] Nelson, J. D. and Miller, D. J. Expansive Soils: Problem and Practice in Foundation and Pavement Engineering", Wiley, New York, 1992.

[9] Eberemu, A. 0, Amadi, A. A. and Lawal, M. "The Geotechnical Properties of Black Cotton Soil Treated with Glass Cullet", Nigeria Journal of Engineering, pp. 23-30. 2012,

[10] Das, M. B. Principles of Geotechnical Engineering, $4^{\text {th }}$ edition PWS Publishing Division of International Thomas Publishing, 1998.

[11] Neville, A. M. Properties of Concrete, $4^{\text {th }}$ edition. Pearson Education Asia Ltd, Malaysia, 2000.

[12] Alhassan, M.and Mustapha, A. M. "Effect of Rice Husk Ash on Cement Stabilized Laterite", Leonardo Electronic Journal of Practices and Technologies, Romania, vol. 6(11), ,pp. 47-58. 2007.
[13] https://www.worldriceproduction.com/13.10.2016.

[14] Oyetola, E.B. and Abdullahi, M. "The use of Rice Husk Ash in Low-cost Sandcrete Block Production", Leonardo Electronic Journal of Practice and Technology (Romania), vol. 8, , pp. 58-70. 2006.

[15] Wailes, E. J. and Chavez, E. C. World Rice Outlook: International Rice Baseline with Deterministic and Stochastic Projections, 2012-2021. Department of Agricultural Economics and Agribusiness, Division of Agriculture, University of Arkansas, 2012.

[16] Raheem, M. O., Otuoze, H. S. and Abdulhafiz, U. "Properties of Rice Husk Ash Stabilized Laterite Roof Tiles", Leonardo Electronic Journal of Practices and Technologies, Issue 23, July-December, pp. 4150. 2013

[17] Akinyele, J. O., Salim, R. W., Oikelome, K. O. and Olateju, 0. T. "The Use of Rice Husk Ash as a Stabilizing Agent in Lateritic Clay Soil", International Journal of Civil, Environmental, Structural, Construction and Architectural Engineering, vol. 9(11): pp. 1373-1377. 2015.

[18] Eberemu, A. 0. "Consolidation Properties of Compacted Lateritic Soil Treated with Rice Husk Ash", Geomaterials, vol. 1, pp. 70-78, 2011.

[19] Negedu, A. M. and Nwakonobi, T. U. "Evaluation of Properties of Makurdi Lateritic Clay-Rice Husk Ash Bricks for Pavements", Civil and Environmental Research, vol. 7(11), pp. 7-16. 2015.

[20] Alabi, A. B., Olutaiwo, A. O. and Adeboje, A. O. "Evaluation of Rice Husk Ash Stabilized Lateritic Soil as Sub-base in Road Construction", British Journal of Applied Science \& Technology vol. 9(4),, pp. 374-382. 2015

[21] Akeke, G. A., Ewa, D. E. and Okafor, F.O. "Effects of Variability in the Pozzolanic Properties of Rice Husk Ash (RHA) on the Compressive Strength of Concrete", Nigerian Journal of Technology vol. 35(4), pp. 694-698. 2016,

[22] Sear L. K. A. "Should you be Using More PFA in Cement Combination for Durable Concrete", Proceeding of the International Conference held at the University of Dundee, Scotland, UK. Edited by Dhir, R. K, Harrison, T. A and Newland, M. D. Thomas Telford Ltd, London, pp. 696. 2005.

[23] Rahman, M. A. "Effect of Rice Husk ash on Geotechnical Properties of Lateritic Soils", West Indian Journal of Engineering, vol. 11(2), pp. 18-24. 1986,

[24] Alhassan, M. "Potentials of Rice Husk Ash for Soil Stabilization”, AU Journal of Technology, Bangkok, Thailand Issue 11(4), pp. 246-250. 2008.

[25] Okafor, F. O. and Okonkwo U. N. "Effects of Rice Husk Ash on Some Geotechnical Properties of Laterite Soil", Leonardo Electronic Journal of 
Practices and Technologies, vol. 15, , pp. 67-74. 2009..

[26] Alhassan, M. "Permeability of Lateritic Soil Treated with Lime and Rice Husk Ash", AU Journal of Technology, Bangkok, Thailand, Issue12 (2), pp.115-120. 2008,

[27] Alhassan, M. "Permeability of Cement-Rice Husk Ash Treated Lateritic Soil", Proceeding of the $1^{\text {st }}$ Biennial Engineering Conference, Federal University of Technology, Minna, Nigeria, pp. 75-79. 2008.

[28] Mtallib, M. O. A. and Bankole, G. M. "The Improvement of the Index Properties and Compaction Characteristics of Lime Stabilized Tropical Lateritic Clays with Rice Husk Ash (RHA) Admixtures", Electronic Journal of Geotechnical Engineering, vol. 16, Bund. I, pp. 983-996. 2011.

[29] Francis, I. A. and Venantus, A. "Models and Optimization of Rice Husk Ash-Clay Soil Stabilization", Journal of Civil Engineering and Architecture, vol. 7(10) (Serial No. 71), pp. 12601266, 2013.

[30] Ayininuola, G. M. and Olaosebikan, O. I. "Influence of Rice Husk Ash on Soil Permeability", Transnational
Journal of Science and Technology, vol. 3(10), pp. 29-33. 2013,

[31] Agwu, U. L. and Akpan P. P. "Comparative Study of the use of Rice Husk Ash, Fly Ash, Periwinkle Shell and Gypsum as Stabilizing Agent for Clay", International Journal of Research and Advancement in Engineering Science, vol. 3(2), , pp. 1-8. 2013.

[32] Isah, H. "The Effect of Rice Husk on the Chemical Properties of Clay Soil", Proceeding of $2^{\text {nd }}$ International Conference on Chemical, Biological, and Environmental Sciences, pp. 9-12. 2015.

[33] Eberemu, A. O. and Sada, H. "Compressibility Characteristics of Compacted Black Cotton Soil Treated with Rice Husk Ash", Nigerian Journal of Technology, Vol. 32(3), pp.507-521. 2013.

[34] Eberemu, A. O. "Desiccation Induced Shrinkage of Compacted Tropical Clay Treated with Rice Husk Ash", International Journal of Engineering Research in Africa, vol. 6, pp. 45-64. 2011.

[35] Agbede, I. 0, and Joel, M. "Effect of Rice Husk Ash (RHA) on the Properties of Ibaji Burnt Clay Bricks", American Journal of Scientific and Industrial Research, vol. 2(4), pp. 674-677. 2011. 